\title{
REVIEW OF ORBITAL EXENTERATIONS IN KORLE-BU TEACHING HOSPITAL
}

\author{
E. ACKUAKU-DOGBE \\ Department of Surgery, Eye Unit, University of Ghana Medical School, P. O. Box 4236, Accra, Ghana \\ Corresponding Author: Dr. Edith Akuaku-Dogbe \\ Email:edithackuaku@yahoo.co.uk
}

Conflict of Interest: None declared

\section{SUMMARY}

Background: Orbital exenteration (OE) is a disfiguring procedure which typically involves removal of the entire contents of the orbit including the periorbita, appendages, eyelids and, sometimes, a varying amount of surrounding skin and bone. It results in devastating functional, aesthetic and psychological losses.

Design: This study reports an experience of $\mathrm{OE}$ in a Teaching Hospital in Accra Ghana.

Method: The records of all patients who underwent OE between November 2005 and October 2009 were reviewed retrospectively. These were cases seen at the orbit and oculoplastic clinic of the eye unit. Results: A total of 25 patients underwent OE. Nineteen $(76 \%)$ of these were for invasive orbital squamous cell carcinomas and six (24\%) were for other cases. Only one patient had $\mathrm{OE}$ for a benign condition (orbital haemangioma). Four patients had lid sparing procedures. One of these was for a patient with extensive ocular surface squamous cell carcinoma. Five patients had recurrent tumours. Among those patients with squamous cell carcinoma, seven had previous procedures, sometimes multiple before reporting to our clinic.

Conclusion: Orbital exenterations in developing countries are mostly for neglected periorbital and ocular surface malignancies. Educating patients to seek medical attention as soon as they notice a persistent conjunctival growth could prevent this.

Keywords: orbital exenteration, orbital tumours, squamous cell carcinoma, sino-orbital fistulae, orbital reconstruction.

\section{INTRODUCTION}

Orbital exenteration (OE) is a disfiguring procedure which typically involves removal of the entire contents of the orbit including the periorbita, appendages, eyelids and, sometimes, a varying amount of surrounding skin and bone. OE results in devastating functional, aesthetic and psychological losses.
It is therefore reserved for the treatment of potentially life-threatening malignancies arising from the orbit, paranasal sinuses or periocular skin. ${ }^{1}$

OE has not been shown to produce a cure in most cases but controls local disease and may prolong life, sometimes, when used with other adjuvant therapy (chemotherapy and radiotherapy). ${ }^{2}$ In developing countries, where patients present with advanced fungating tumours, the procedure may improve the quality of life for the rest of their life time. Occasionally it has been used in the management of benign tumours or orbital infections refractive to other modes of treatment. ${ }^{2,3}$ Often the orbit is reconstructed to improve cosmesis and also to facilitate the application of prosthesis.

Among several classifications of $\mathrm{OE}$ is that by Meyer and Zaoli who, in 1971, classified OE into four categories in relation to the extent of destruction involved in the surgery ${ }^{4}$ as follows:

Type I: palpebral skin and conjunctiva are spared;

Type II: only the palpebral skin is spared and the eyeball and its appendages are removed with the conjunctiva;

Type III: both eyelids are removed with orbital contents;

Type IV: the eyeball, eyelids and appendages of the eye are removed with the involved bone structures.

Yeatts divided OE into 2 categories (a) total exenteration which involves the removal of the entire orbital content with or without sacrifice of the eyelid skin and (b) subtotal involving partial removal of orbital tissues with sacrifice of the eye. ${ }^{5}$ Other classifications have been developed by Cordeiro and Santamaria. ${ }^{3,6}$ Several techniques for cosmetic repair have also been described. $^{7-10}$ However in some cases the orbit is left to granulate. ${ }^{3}$ This study reports our experience of $\mathrm{OE}$ in a Teaching Hospital in Accra, Ghana. 


\section{METHODS}

The records of all patients who underwent OE between November 2005 and October 2009 were reviewed retrospectively. These were cases seen at the orbit and oculoplastic clinic of the eye unit. All patients had biopsy and CT scan evaluation before surgery. The orbit was left to granulate in all patients. Tumours from adjacent structures invading the orbit, retinoblastomas and burkits lymphomas in children were not managed in this clinic. Patients with recurrence or histological suggestion of incomplete excision were referred for radiotherapy. Data was collected from histopathological reports, and case note.

Data for all exenterations performed and their diagnosis were obtained from theatre records. Some case notes were missing and some patients defaulted in follow up. Data was therefore incomplete for some patients. Data on Age, sex, clinical presentation, indications for surgery, histopathological diagnosis, HIV status, adjuvant treatment and outcome was collected. As data was missing for some patients, each set of data was analysed separately.

\section{RESULTS}

A total of 104 patients with malignant tumours of the orbit and adnexa were seen during the period under review (data unpublished). Sixty eight of these were orbital tumours. Twenty five of the orbital tumours were orbital extensions of ocular surface or eyelid squamous cell carcinomas (SCC). Six cases of SCC were found to be too advanced and would not benefit from surgery. These were referred for radiotherapy.

None of them showed signs of regression during the period of follow up and were subsequently lost to follow up. The youngest patient for $\mathrm{OE}$ was 11 years and the old- est 88 years. The $\mathrm{M}: \mathrm{F}=1: 2.6$. Age sex distribution is found in Table 1

Table 1 Age and sex distribution

\begin{tabular}{|c|c|c|c|}
\hline Age & Male & Female & Total (\%) \\
\hline $10-25$ & - & 4 & $4(16)$ \\
\hline $26-40$ & 1 & 6 & $7(28)$ \\
\hline $41-55$ & 4 & 5 & $9(36)$ \\
\hline $56-70$ & 2 & 1 & $3(12)$ \\
\hline $70+$ & - & 2 & $2(8)$ \\
\hline TOTAL & $\mathbf{7 ( 2 8 \% )}$ & $\mathbf{1 8 ( 7 2 \% )}$ & $\mathbf{2 5}$ \\
\hline
\end{tabular}

Out of 25 patients who underwent OE 19 (76\%) were for invasive orbital squamous cell carcinomas and six (24\%) were for other cases including one patient with a benign condition (orbital haemangioma) (Tables 2 and 3 ). Four patients had lid-sparing procedures (Table 2).

Table 2 Characteristics of Orbital Exenteration in patients other than SCC

\begin{tabular}{|c|c|c|c|c|c|c|c|}
\hline Age & Sex & $\mathbf{R} / \mathbf{L}$ & Presentation & Diagnosis & HIV Status & Operation & Result \\
\hline 22 & $\bar{F}$ & $\mathrm{~L}$ & $\begin{array}{l}\text { Orbital mass } \\
\text { Disorg. Ant seg }\end{array}$ & $\begin{array}{l}\text { Uveal Malignant mela- } \\
\text { noma }\end{array}$ & Positive & Lid Sparing & Recurrent \\
\hline 31 & $\mathrm{~F}$ & $\mathrm{~L}$ & Orbital tumour & Adenoid cystic ca & Not Known & Total & Ref/Lost \\
\hline 20 & $\mathrm{~F}$ & $\mathrm{R}$ & Orbital tumour & Chondrosarcoma & Negative & Lid Sparing & Recurrent \\
\hline 35 & $\mathrm{~F}$ & $\mathrm{~L}$ & $\begin{array}{l}\text { Pagetoid upper } \\
\text { lids, fornix, ant } \\
\text { orbit }\end{array}$ & Sebaceous carcinoma & Positive & Total & Healed \\
\hline 11 & $\mathrm{~F}$ & $\mathrm{~L}$ & $\begin{array}{l}\text { Massive orbital } \\
\text { Tumour with blind } \\
\text { eye }\end{array}$ & $\begin{array}{l}\text { Complex congenital } \\
\text { orbital haemangioma }\end{array}$ & Negative & Lid Sparing & Healed \\
\hline 14 & $\mathrm{~F}$ & $\mathrm{R}$ & Sino orbital tumour & $\begin{array}{l}\text { Alveolar Rhabdomyo- } \\
\text { sarcoma }\end{array}$ & Negative & Total & Ref/Lost \\
\hline
\end{tabular}

One of these was for a patient with extensive ocular surface squamous cell carcinoma (patient 14, Table 3). The rest had total OE. It is difficult to report on the outcome because of the large numbers lost to follow up and incomplete data. With the available data (Tables 2 and 3), $10(40 \%)$ of the 25 patients were lost to follow up, some of these were referred for radiotherapy and/or chemotherapy. Five patients had recurrent tumours some with extension to adjacent structures. Ten patients healed completely some with adjuvant radiotherapy, as at last follow up (for periods ranging from 4 to 8 months). 
The commonest complication was sino-orbital fistulas, which were recorded in $5(20 \%)$ patients. In the patients with squamous cell carcinoma, at least seven patients had previous procedures, sometimes multiple before reporting to our clinic (Table 3 ).

Table 3 Characteristics of Orbital Exenteration in patients with SCC

\begin{tabular}{|c|c|c|c|c|c|c|}
\hline No & Age & Sex & $\begin{array}{l}\text { HIV sta- } \\
\text { tus }\end{array}$ & Tumour Extent & $\begin{array}{l}\text { Previous Ex- } \\
\text { cision }\end{array}$ & Outcome \\
\hline 1. & 29 & $\mathrm{~F}$ & Pos & Lost data & Lost data & Fistular/healed \\
\hline 2. & 46 & M & Positive & Lost data & Yes & Lost \\
\hline 3. & 42 & $\mathrm{~F}$ & Positive & Medial bulbar/ant orbit/ocular & 2 yes & Healed \\
\hline 4. & 42 & M & Negative & Entire ocular surface/no ocular & Lost data & Fistular/healed \\
\hline 5. & 42 & $\mathrm{~F}$ & Negative & $\begin{array}{l}\text { Previous enucletion/eyelid/entire } \\
\text { orbit }\end{array}$ & $\begin{array}{l}\text { Yes+enucleati } \\
\text { on }\end{array}$ & Fistular/lost \\
\hline 6. & 39 & $\mathrm{~F}$ & Positive & $\begin{array}{l}\text { Fungating conj/proptosis/entire } \\
\text { orbit/ocular }\end{array}$ & No & Lost \\
\hline 7. & 44 & $\mathrm{~F}$ & Positive & $\begin{array}{l}\text { Entire ocular surface/ant or- } \\
\text { bit/ocular }\end{array}$ & Yesx 4 & Lost \\
\hline 8. & 36 & $\mathrm{~F}$ & Positive & $\begin{array}{l}\text { Entire ocular surface/inf forni- } \\
\text { ceal/ }\end{array}$ & Nil & Healed \\
\hline 9. & 56 & M & ? & $\begin{array}{l}\begin{array}{l}\text { Fungating tumour } \\
\text { bital/ocular/ }\end{array} \\
\end{array}$ & No & Lost \\
\hline 10. & 28 & M & Positive & Entire Ocular surface & Lost data & Healed \\
\hline 11. & 50 & M & Negative & $\begin{array}{l}\text { Mid temp. bulbar/inf ant orb./no } \\
\text { ocular }\end{array}$ & Yes & $\begin{array}{l}\text { Cervical lymph. } \\
\text { No loc } \mathrm{Al} \\
\text { rec/fistular/ }\end{array}$ \\
\hline 12. & 45 & $\mathrm{M}$ & Positive & Large Lower fornix obsc, eye & No & Rec/max/died \\
\hline 13. & 69 & $\mathrm{~F}$ & Negative & Fungating orbital/ocular & Lost & Intracranial ext. \\
\hline 14. & 88 & $\mathrm{~F}$ & Lost data & $\begin{array}{l}\text { Large medial bulbar/ant. Inf. Or- } \\
\text { bit. No ocular }\end{array}$ & Lost data & Lost data \\
\hline 15. & 27 & $\mathrm{~F}$ & Positive & Palpebral conjunctivitis & $\begin{array}{l}\text { Yes+eviscerat } \\
\text { ion }\end{array}$ & Healed \\
\hline 16. & 61 & M & Negative & $\begin{array}{l}\text { Entire bulbar/anterior or- } \\
\text { bit/ocular }\end{array}$ & Nil & Healed \\
\hline 17. & 46 & $\mathrm{~F}$ & Negative & $\begin{array}{l}\text { Large bulbar/ocular/anterior or- } \\
\text { bit }\end{array}$ & Yes $2 \mathrm{x}$ & $\begin{array}{l}\text { Rec/fistular/max } \\
\text { ext. }\end{array}$ \\
\hline 18. & 80 & $\mathrm{~F}$ & Negative & $\begin{array}{l}\text { Fungating tumour arising from } \\
\text { conjunctiva }\end{array}$ & Lost data & Lost data \\
\hline 19. & 50 & $\mathrm{~F}$ & Lost data & Lost data & Lost data & Lost data \\
\hline
\end{tabular}

$\mathrm{Rec}=$ tumour recurrence; fistula $=$ sino-orbital fistula; max ext=maxillary extension

\section{DISCUSSION}

Orbital exenterations (OE) are commonly performed with various techniques (myocutaneous flaps implantation, eyelid-sparing exenteration with myocutaneous flap, and dermis fat implants) to improve cosmesis. ${ }^{7-10}$ These techniques offer rapid healing and provide for the application of prosthesis. However they are not suitable in cases where tumour recurrence is likely. Sometimes the orbit is left to granulate., 
The latter technique was chosen in all our patients because of the extent of the tumors seen and the possibility of high recurrence rates. Moreover this technique is simple and produces cosmetically better results for patients not wearing prosthesis. Spontaneous granulation technique is employed for cases where tumour clearance is not guaranteed. Others would employ instead delayed orbital reconstruction ${ }^{12}$ using dermis-fat graft and temporalis transfer. But even these techniques are usually reserved for more benign and less aggressive tumours. ${ }^{10,12-14}$

A majority of patients $(76 \%)$ in this study were neglected invasive squamous cell carcinomas (SCC) arising from the conjunctiva invading the orbit. Although conjunctival SCC is known to be relatively nonaggressive tumour, especially in Caucasians, a few studies from tropical and subtropical regions suggest that in these areas, this type of cancer behaves in an aggressive fashion and tends to affect younger individuals. $^{14,15}$ This study supports these reports in that there was extensive orbital invasion of conjunctival SCC in our patients.

A good proportion of the patients had had previous surgeries for earlier stages of conjunctival lesions ranging from single or multiple excisions to evisceration and enucleations. Some of these tumours subsequently invaded the eyeball and the orbit. This situation highlights the lack of adequate management of early stages of SCC and lack of follow up on these patients. Maheshwari reported a similar situation in an Indian study. ${ }^{3}$

It is not possible to comment on survival rates of our patients because of poor follow up. Some of these patients might have died at home since some come from places very far from our centre. In a study among elder patients who had OE in Italy, Groce et al reported a high rate of tumour related - mortality ( 5 out of 7$).^{2}$ These were in patients with multiple recurrent cases; three of these were from SCC. This and other studies suggest that $\mathrm{OE}$ tends to be palliative for advanced tumours. With the high rate of default in follow up attendance in developing countries, these situations are not uncommon. Some end up with practitioners of alternative medicine and die in their hands. However other studies report improved mortality with more radical surgery combined with adjuvant therapy. ${ }^{12}$

The only complication we had was sino-orbital fistulae. This is the commonest complication of OE reported in literature. ${ }^{16}$ Sino-orbital fistulae are commoner following post-operative radiotherapy but may occur when there is damage to the thin medial wall or floor of the orbit.
It may be repaired with muscle flaps or skin graft. In our cases, they were left to heal over several weeks. Others have reported leaking cerebrospinal fluid and socket shrinkage. ${ }^{3}$

Other studies on OE reported fewer numbers, the majority were for lesions affecting the orbit. A study from India reported $15 \mathrm{OE}$ in a ten year period, 54\% originating from the eyelids, $33 \%$ from the orbit and $13 \%$ from the conjunctiva ${ }^{3}$. Most of their cases were also for neglected tumours that could have been spared $\mathrm{OE}$ if patients had been seen earlier. In a study in Turkey spanning a period of 30 years, 429 cases of OE were reported $^{11} 40 \%$ of which were for tumours of eyelid origin and only $13 \%$ for primary conjunctival tumours. However SCC was the most frequent indication for $\mathrm{OE}$, accounting for over $30 \%$ of all cases.

Basal cell carcinomas have been reported as the major indications for $\mathrm{OE}$ in these and other studies. ${ }^{(2,9,10)}$ Other studies from tropical regions show a preponderance of SCC as indication for $\mathrm{OE}^{3}$. In this study most of our patients had neglected ocular surface SCC. It has been suggested that people in tropical regions are predisposed to squamous cell carcinoma of the conjunctiva due to solar radiation and high prevalence of HIV. Also in areas where eye care services are inadequate patients tend to present late with tumours of the eye and adnexa. This may account for the large numbers of people requiring $\mathrm{OE}$, and requiring $\mathrm{OE}$ for secondary tumours as opposed to primary orbital tumours in developed countries.

There is a preponderance of females in this study. It has been suggested that women in deprived areas are disadvantaged when it comes to eye care. They depend on their husbands for permission and financial support. These are usually denied till late in the course of the disease.

Limitations of this study include incomplete data for some of the patients due to poor follow up records. The retrospective nature of the study of the study is also a major limitation

\section{CONCLUSION}

This study discusses an experience with orbital exenteration in a developing country with limited resources and late presentation of most patients. It supports other studies suggesting that orbital exenterations in developing countries are most of the time performed for neglected periorbital and ocular surface malignancies. Educating patients to seek early medical attention for persistent conjunctival growths could prevent this. Conjunctival tumours should be adequately managed at first presentation to prevent recurrences, which are 
more aggressive and more likely to invade the eye and orbit.

\section{REFERENCES}

1. Nassab RS, Thomas SS, Murray D. Orbital exenteration for advanced periorbital skin cancers: 20 years experience. J Plast Reconstr Aesthet Surg. 2007, 60:1103-9

2. Croce A, Moretti A, D’Agostino L, Zingariello P. Orbital exenteration in elderly patients: personal experience. Acta Otorhinolaryngo Ital. 2008 Aug; 28(4);193-9

3. Maheshwari R, Review of orbital exenteration from an eye care centre in Western India. Orbit, 2010 Feb; 29(1) 35-38

4. Radici M, Bacciolo G, Palma O, Bozza f, Il massiccio faciale In: De CamporaE, Marzetti F, editors: La chinugia Oncologica della testa e del collo. Pisa: Pacini Editoore; 1996; 345-81

5. Yeatts RP, The esthetics of orbital exenteration. Am J ophthalmol 2005;139:152-3

6. Cordeiro PG, Santamaria E. A classification system and algorithm for reconstruction of maxillectomy anmidfacial defects. Plast Reconstr. Surg. 2000; 105:2331-48

7. Menderes A, Yilmaz M, Vayvada H, Demirdover C. Baruten A. Reverse temporalis muscle flap for the reconstruction of orbital exenteration defects. Ann. Plat. Surg. 2002; 48:521-7
8. Looi A, Kazim M, Cortes M, Rootman J. Orbital reconstruction after eyelid and conjunctiva sparing orbital exenteration. Ophthal Plast Reconstr Surg. 2006 Jan-Feb; 22(1):1-6

9. Nassab RS, Thomas SS, Murray D. Orbital exenteration for advanced periorbital skin cancers: 20 years experience. J Plast Reconstr Aesthet Surg. 2007; 60(10):1103-9

10. Croce A, Moretti A, D’Agostino L, P. Orbital exenteration in elderly patients: personal experience. Acta Otorhinolaryngo Ital. 2008 Aug; 28(4);193-9

11. Gunalp I, Gunduz K, Duruk K. orbital exenteration: a review of 429 cases. Int Ophthalmol. 19951996; 19(3):177-84

12. Lin HF, Lui CC, Hsu HC, Lin SA. Orbital exenteration for secondary orbital tumours: a series of seven cases. Chang Gung Med J.2002 Sep;25(9):599-605

13. Menderes A, Yilmaz M, Vayvada H, Demirdover C. Baruten A. Reverse temporalis muscle flap for the reconstruction of orbital exenteration defects. Ann. Plat. Surg. 2002; 48:521-7

14. Blodi FC. Squamous cell carcinoma of the conjunctiva. Doc Ophthalmol. 1973;34:93-108.

15. Johnson TE, Tabbara KF, Robert G. et al. Secondary Squamous Cell Carcinoma of the Orbit Arch Ophthalmol 1997; 115:75-78

16. Rahman I, Cook AE, Leatherbarrow B. Orbital exenteration: a 13-year Manchester experience. $\mathrm{Br}$. J Ophthalmol. 2005;89:1335-1340 